\title{
Critical Periods of Aflatoxin Contamination of Maize during Post-Harvest Management in Velingara (Senegal)
}

\author{
Eliasse dieme ${ }^{1,3^{*}}$, Ibrahima sarr ${ }^{2}$, Maty diop ${ }^{1,3}$, Cheikh ndiaye ${ }^{1}$, Malang seydi ${ }^{3}$ and Djibril traore ${ }^{1}$ \\ ${ }^{1}$ Institut de Technologie Alimentaire, BP 2765, Dakar, Sénégal. . \\ 2.Institut Sénégalais de Recherche Agricole (ISRA), BP 3120 - Dakar. \\ 3.Université Cheikh Anta Diop, Faculté des Sciences et Technique, Département de Biologie végétale, BP 5005, Dakar, \\ Sénégal. 6EISMV de Dakar, BP 5077, Dakar, Sénégal.
}

Received: 16 November, 2018; Accepted: 26 December, 2018; Published: 11 January, 2019

*Corresponding author: Eliasse dieme, Université Cheikh Anta Diop, Faculté des Sciences et Technique, Département de Biologie végétale, BP 5005, Dakar, Sénégal. 6EISMV de Dakar, BP 5077, Dakar, Sénégal; E-mail: eliassedim@yahoo.fr

\begin{abstract}
Contrasting with the favorable climatic and environmental conditions, improper post-harvest management of cereals is often responsible for high levels contamination of aflatoxin in Africa. This study aimed at identifying critical periods of aflatoxin concentrations in cereals. Thus, a survey followed by sampling at each stage of production for aflatoxin quantification using the AFLA-V AQUA test procedure (0$100 \mathrm{ppb}$ ) was carried out at different farmer sites in Velingara.
\end{abstract}

The survey revealed that only $9.36 \%$ of farmers were aware of molds and aflatoxin. Quantification of aflatoxin revealed that only $4.9 \%$ of farmers had contaminated crops in the first stage of harvest (ears drying). However, during traditional storage, the contamination rate increased up to $39 \%$, proportional to the aflatoxin level that reaches $70 \mathrm{ppb}$. Two stages of the post-harvest management were particularly critical in the accumulation of aflatoxin in cereals: drying, especially the bare cobs and storage.

Keywords: Traditional farmers; Postharvest management; Aflatoxin;

\section{Introduction}

Since cereal cultivation in Africa is mainly rain-fed, the level of yields is strongly affected by rainfall fluctuations. In addition to this dependence, post-harvest grain management is poorly ensured. This management is responsible for a high rate of postharvest losses and a lack of quality due mainly to the presence of molds of the genus Aspergillus (Aspergillus flavu, A. parasiticus and A. nomius) producing aflatoxin at the level of cereal production. Aspergilli are ubiquitous fungi in hot and humid environments (tropical and intertropical climate) [1,2]. But conditions for the production of aflatoxin are narrower than those favoring fungal growth. Aflatoxins represent major challenges for global systems for food security, health, nutrition and the economy [3]. In general, informations on the prevalence of aflatoxin in Africa are limited. But available dataindicate that aflatoxin levels often exceed the established tolerance limits for basic foods such as cereals.
Among cereals, maize is one of the most favorable substrates for the proliferation of toxigenic molds and aflatoxin contamination. This is mainly due to its composition and the high moisture content during harvest on the one hand, and the precarious conditions of its post-harvest management in subSaharan Africa (ECOWAS) [4]where its cultivation is the preserve of small farmers on the other hand [5]. Structures such as PACA (African Partnership for Aflatoxin Control) have developed strategies to counter the presence of aflatoxin in foods such as maize. These strategies include a precise knowledge of the sensitive points at the origin of the contamination. The work we are proposing aims to identify the incriminated steps in the high contamination of maize with aflatoxin. This work was carried out in the department of Velingara (Senegal) with the support of ANCAR (National Agency for Agricultural and Rural Council) agents from the said locality and under the supervision of ISRA Bambey and the Purdue university team.

\section{Material and Method}

\section{Investigation}

Producers who planted maize in 2015 in randomly selected villages in the 9 communes of Velingara (Figure 1), constituted the target population of this study. The sampling plan was stratified at three levels in the department: rural commune, village and household / producer. The list of all municipalities and villages wasacquired by GIS analysis. A survey of a rate of 7\% (weighting) was applied for the number of villages per municipality. A total of 308 producers were interviewed between 13 and 20 October 2015 using a questionnaire entered into Survey Be software installed in a tablet. The questions focused on harvesting, transport, drying techniques and storage methods. Then the data were exported to Excel for analysis. 


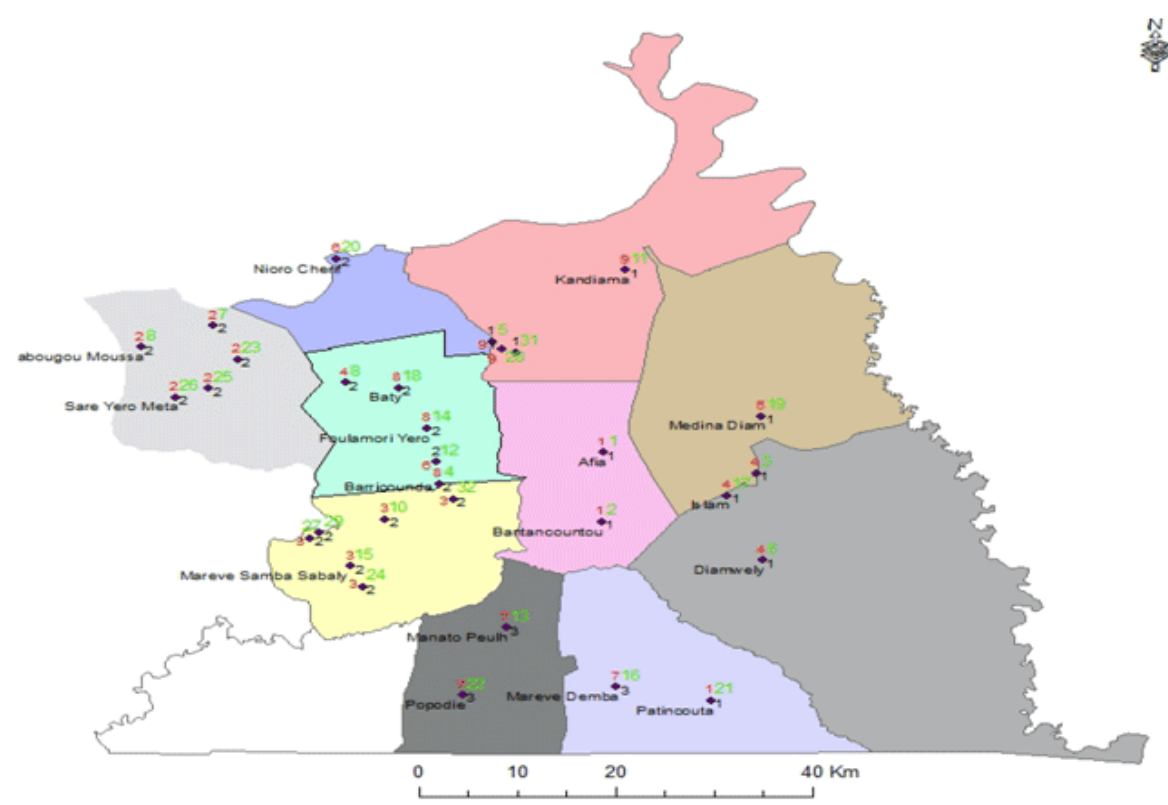

Figure 1: Location of the various villages surveyed in the Velingara department

\section{Sampling}

Field samples as well as those representing post-harvest management stages were collected from each producer visited. A total of six types of samples were listed: un harvested maize (five ears / sample randomly collected), naked maize ears spreaded indoors and dried outdoors naked maize ears (five ears / sample), spreaded deseeded maize on the inside, dried maize on the outside and stored maize samples ( $500 \mathrm{~g} /$ sample). These samples were taken at the level of each farmer visited following the post-harvest management stage. Each sample was provided with a label on which was noted its nature, the place of harvest and the date of harvest all introduced into a sealed plastic bag. Two types of studies are applied to these samples: a macroscopic diagnosis to inventory the molds and a quantification of aflatoxin in maize.

\section{Corn moisture}

Maize moisture was studied during harvest and throughout its post-harvest trajectory. Rapid tests using the moisture meter were performed on non-harvest maize samples, naked corncobs, deseeded maize and stored maize. Humidity levels were obtained using the XLSTAT 6.1.9 software.

\section{Quantification of aflatoxin}

The quantification of aflatoxin was done on the UN harvested maize samples and the naked dried ears suspected during the macroscopic diagnosis in addition to a few selected at random. On the other hand, this quantification is done on all samples of deseeded dried maize and stored maize.

The quantification of aflatoxin in maize samples was done using the following AFLA-V AQUA Test Procedure (0-100 ppb): 5 grams of crushed maize samples were mixed at $25 \mathrm{ml}$ solution of AQUA Premix in a test tube. The mixture is stirred for 2 minutes and then filtered with a filter paper. Using a micropipette, 0.1 $\mathrm{ml}$ of the filtrate was diluted in $0.1 \mathrm{ml}$ of Afla- $\mathrm{V}$ diluent in an Eppendorf tube. This solution thus obtained was stirred for 20 seconds and then $0.1 \mathrm{ml}$ transferred into the round opening of the Afla-V strip with a flow rate of one drop per second. The strip was left standing for 5 minutes (the reaction's time) on a flat, horizontal surface protected from any airflow. The strip was then introduced into the Vertu reader which displays directly on the screen the amount of aflatoxin in the sample. We performed this quantification on corn samples from the different stages of its post-harvest management. A total of 110 samples including 21 samples of non-harvested maize, 20 samples of dried naked corncobs, 38 samples of deseeded maize and 31 stored maize samples were tested with aflatoxin.

For the interpretation of our results we have calculated using the XLSTAT software the level of contamination (Tcaf) in maize's aflatoxin at each stage and the mean and the standard deviation.

\section{Results}

\section{Post-harvest behavior of farmers}

The results of the survey reveal that maize harvesting is manual for all farmers. A very large proportion of them immediately dry the corn in the field after harvest, few bring it at home. Maize drying is mainly done in two areas: on huts and racks or directly on the ground (Figures 2 and 3).

The drying places and the techniques are therefore varied. The survey found that many producers have not yet established new maize stocks (Table 1). 


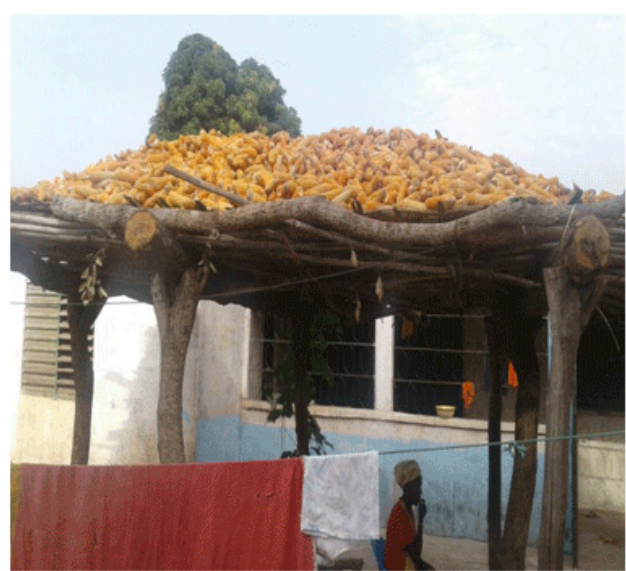

Figure 2: Drying corn on a rack

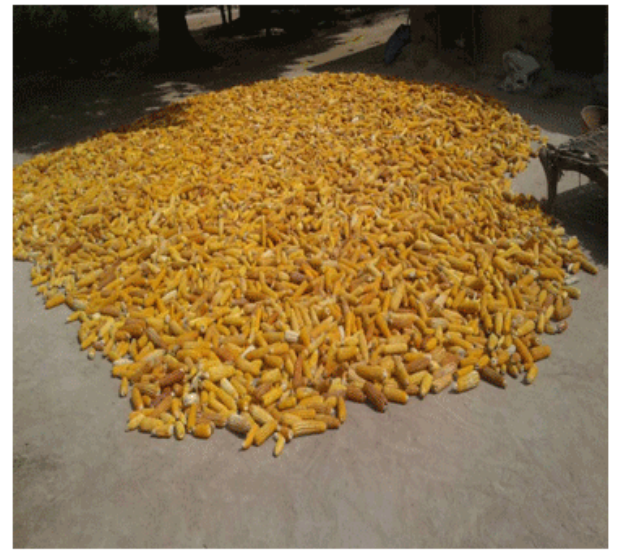

Figure 3: Drying corn on the floor

\begin{tabular}{|c|c|c|c|c|c|c|c|}
\hline Table 1: Post-harvest management of maize \\
$\begin{array}{c}\text { Management } \\
\text { technique }\end{array}$ & Manualharvest & Immediatdrying & Field drying & Brought home & Earsoutside & Earsinside & New stocks \\
\hline \% Farmers & 100 & 97.31 & 96.40 & 3.59 & 20.15 & 14.11 & 26.88 \\
\hline
\end{tabular}

The survey also showed that almost all farmers in this area are untrained. The majority of these farmers have neither knowledge of molds nor of aflatoxin. The use of pesticides is not widespread and remains the apanage of a minority of peasants who are more concerned with the deterioration of maize by insects than its contamination by aflatoxin (Table 2). This lack of training and this lack of awareness of plague lead farmers to a post-harvest behavior that has a certain negative impact on the quality of stored maize.

Table 2: Aflatoxin control

\begin{tabular}{|c|c|c|c|c|}
\hline Aflatoxin control & Mold knowledges & Aflatoxin knowledges & Pesticide & Training \\
\hline \%Fermers & 30.13 & 22.61 & 26.37 & 9.36 \\
\hline
\end{tabular}

\section{Maize moisture during post-harvest management}

The moisture of the corn at harvest is very high. It is on average $34.2 \%$. This high moisture content of corn makes it difficult to take care of post-harvest. Indeed the very long drying process causes its gradual decrease. From this rate, the corn moisture during this process gradually decreases and is $26.3 \%$ in the naked corncobs drying, $18.7 \%$ in the deseeded corn drying and $14.2 \%$ in average for stocked maize (Figure 3). The drying techniques used by farmers in this area only allow very slow dehydration for a long time. This dehydration of corn is insufficient for adequate storage. In general, the maize stocked by farmers has a high humidity. This stored corn moisture remains favorable for the multiplication of insects and especially toxin-producing molds.

\section{Maize aflatoxin contamination rate}

Contamination rates of maize by aflatoxin during the postharvest management process in Velingara are shown in the (Figure 4) below.
A simple analysis of our results shows that the accumulation of aflatoxin in maize beans starts at the drying stage (bare ears dried inside or outside) following the corn harvest with respective rates. 4.9 And $11.1 \%$, and increases during its postharvest itinerary. As a result, the rate of aflatoxin contamination of maize stored for consumption or trade in this area is high at $38.7 \%$.

The contamination rate of outdoor corn is greater than that of indoor dried corn for naked died ears and for deseeded maize. However, neither of these two types of treatment is appropriate for controlling the accumulation of aflatoxin in maize beans even if it is slightly slowed down by drying, especially indoors (a rate of $4,9 \%$ for indoor-dried ears against $11.1 \%$ for externally-dried ears, $14.3 \%$ for deseeded indoor-dried maize against 33.3\% for deseeded externally-dried maize). 


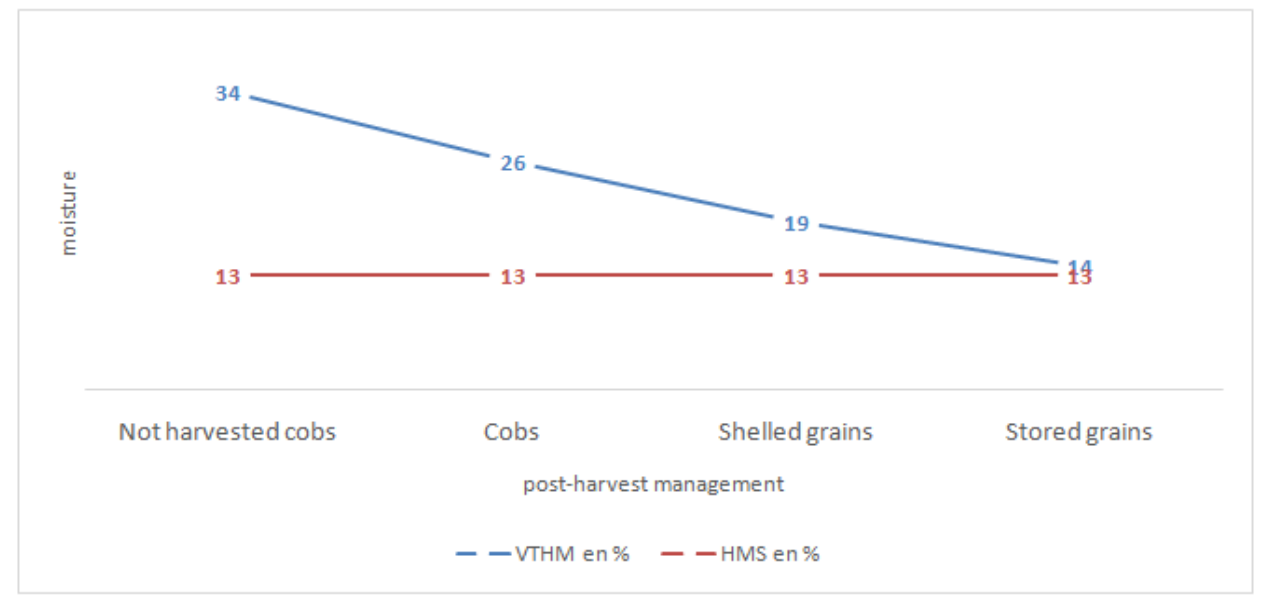

Figure 3: Variation of corn moisture during post-harvest management in Velingara

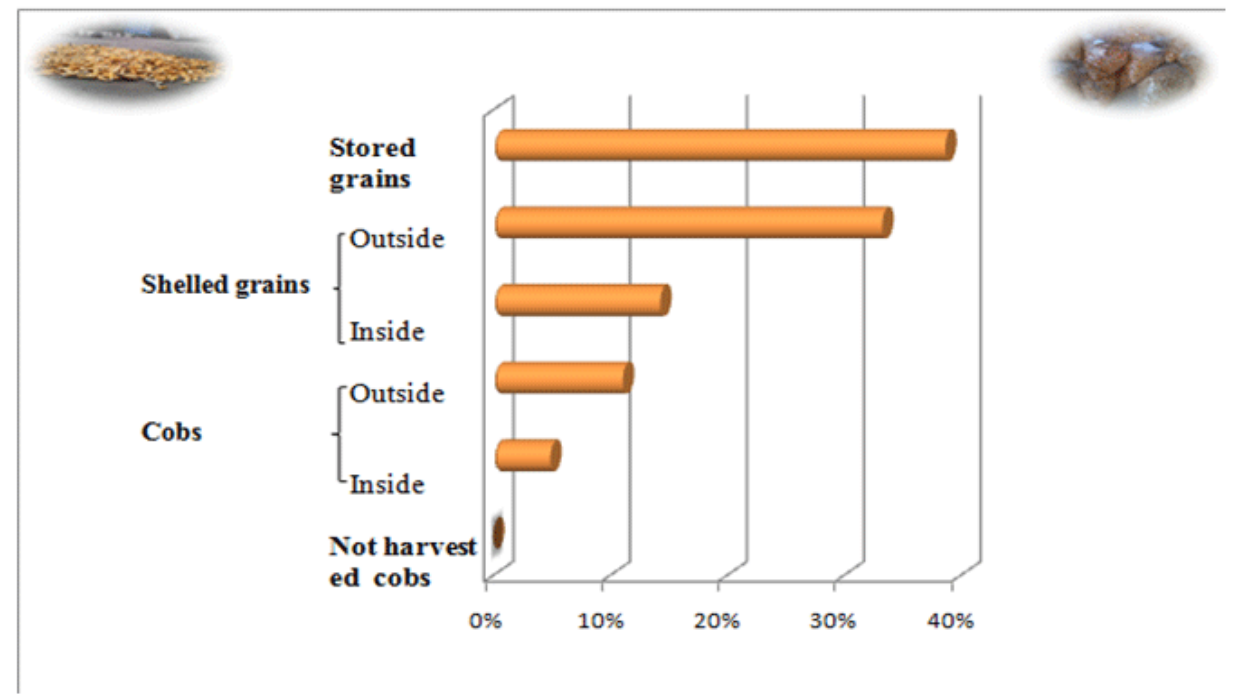

Figure 4: Contamination of corn by aflatoxin during the post-harvest management process in Velingara season 2015-2016.

\section{Aflatoxin content in maize}

The concentration of aflatoxin in maize varies from one sample to another according to drying and storage techniques used by agricultures and are sometimes very high exceeding $1000 \mathrm{ppb}$.

The greatest difference in level of aflatoxin contamination is noted for naked maize ears spread inside houses. In this type of treatment, where we found the lowest contamination rate $(4.9 \%)$, the amount of aflatoxin varied from 1.5 to more than $1000 \mathrm{ppb}$. It is in this type of corn that we found the lowest amount of aflatoxin but also the highest concentration. This situation could be explained by the variety of treatments and the microclimate effect in which this maize is. Inside the houses, maize, which is at a high moisture level after harvest, undergoes different treatments depending on the farmers. It is sometimes piled in a corner, sometimes spread out or suspended with the help of stick under the influence of the smoke. These different aspects expose corn more or less to a proliferation of Arpergillus and to aflatoxin contamination. The difference in contamination values is also noted at the level of deseeded maize spread in the interior but at low proportions compared to those of the naked maize ears. In fact, the drying of deseeded maize inside is done almost in the same way in this zone. Most often corn is spread on canvases on the ground or at mid-height. In addition the deseeding activates do not concern the ears of corn whose grains are denatured (change of color, advanced alteration by insects, or presence of suspicious filaments). On the other hand, the difference between 
the contamination values of the naked maize ears and deseeded externally-dried maize is very low (14 to $53 \mathrm{ppb}$ and 3.8 to 36 $\mathrm{ppb}$, respectively). In this case, maize is only under the influence of environmental conditions. Whatever the farmer, the drying techniques are practically the same. So the conditions for maize contamination by aflatoxin are almost similar. The explanation for this difference in aflatoxin levels could be attributed to the diversity of maize varieties grown in this area. In the case of stored maize, the difference in aflatoxin levels is relatively large ( 2.4 to $800.7 \mathrm{ppb}$ ). The most influential parameters that cause this difference are the duration of storage; storage conditions and water content. These parameters are different from one farmer to another and are interdependent. Corn storage in this area is frequently done in cloth bags. In our study we noted a significant accumulation of aflatoxin (up to more than $800 \mathrm{ppb}$ ) for example in the previous season maize stored in polypropylene bags.

Our study showed that nearly half of the corn stored in this area is contaminated with a mean aflatoxin content of $63.94 \mathrm{ppb}$. This accumulation of aflatoxin causes that a significant amount of maize produced and stored in this area $(25.80 \%)$ for human consumption or for sale is not in compliance with international regulations or standards about aflatoxin.

Since maize is a staple food in Velingara, a high level of aflatoxin is unacceptable for human health. But in countries like Senegal, maize management is informal because it is done by small, untrained farmers. Almost all the farmers we met in our study do not recognize the presence of aflatoxin in corn. All the techniques used in post-harvest management are turned towards preserving the quantity (preventing the attack of insects and rodents) of maize. These farmers do not care about the presence of aflatoxin in their production. Thus, more than $25 \%$ of maize with a high amount of aflatoxin, mixed with the rest of the production are sold in local markets or consumed by the farmers themselves. The aflatoxin contamination of maize, which is one of the most popular cereals in Velingara, does not therefore directly affect its availability or its regularity in the market, but rather poses a public health problem.

Finally, the postharvest way of maize in Velingara is at the origin of its high contamination by aflatoxin. This way is composed of three major stages (drying of naked ears, drying of deseeded maize and storage) with varying degrees of influence on the corn content of aflatoxin. Overall, the average aflatoxin content of maize seed is slightly lower compared to that of dried naked ears and that of stored maize. In fact, the sort performed before the deseeding of the ears has made possible to reduce the aflatoxin content of the maize slightly. The high moisture content due to inadequate drying of maize and poor storage conditions amplifies this content in stored maize (Figure 5). Thus, these two stages of post-harvest management of maize (drying of the naked ears and storage of maize) remain the most sensitive points in the contamination of this cereal by aflatoxin in this area where the farmers use during these different stages almost the same techniques and methods of post-harvest management.

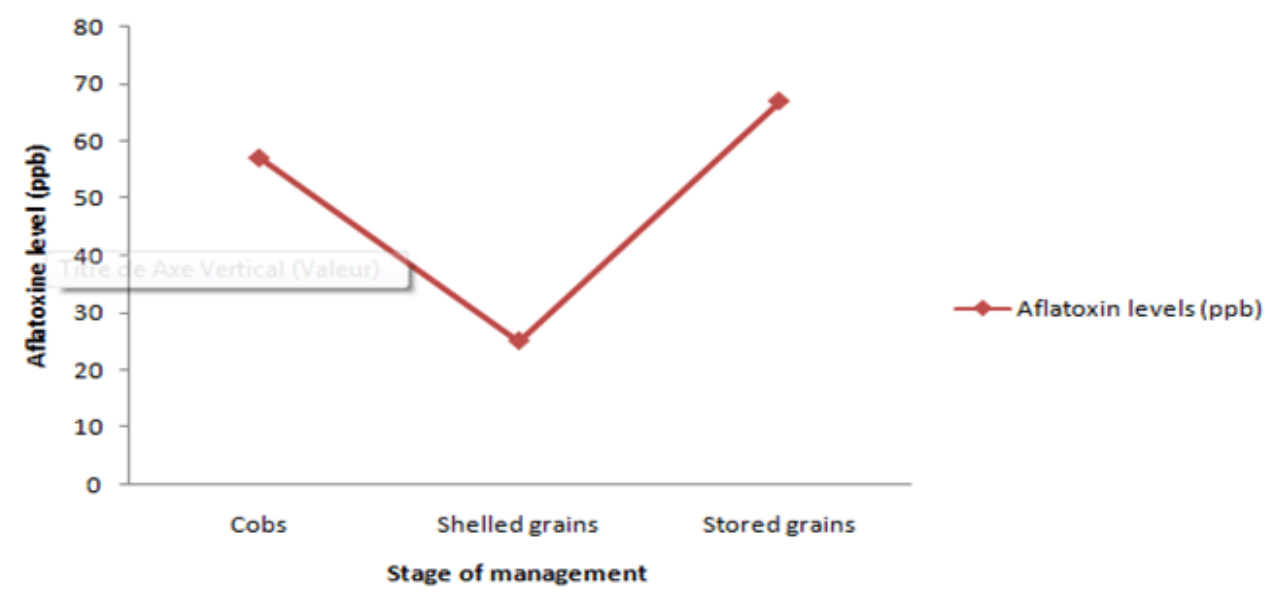

Figure 5: Evolution of the average aflatoxin concentration of maize during its post-harvest management in Velingara.

\section{Discussion}

The molds that we have recorded in the non-harvested mature maize and in the dried naked ears of Velingara belong to the genus Aspergillus and Fusarium. This preponderance of these molds is more marked at the level of the dried naked ears as well as the attack of the insects. The presence of Fusarium follows the logic of James [6] who call them "ear molds". This characteristic of these molds is recounted by various studies in Africa including that of [7] in Kenya. A. flavus is almost non-existent in the nonharvested mature maize. Its remarkable presence at the level of the naked ears is related to the conditions and to a technique of drying which consists of spreading them on the ground. According to [8,9] soil constitutes in Africa, a primary inoculum for Aspergillus contamination of commodities such as maize or 
peanut because they are well adapted and survive in the form of sclerotia, conidia or hyphae. So in addition to the favorable agroecological conditions, our study showed that the contamination of maize by these molds is favored by post-harvest practices of farmers. In the same wake, [10] showed that storage of harvested grain with $>10 \%$ moisture content for extended periods of time in inadequate facilities causes mold growth in the grain. This type of finding is common to the study of mold contamination of maize grown throughout Africa such as that of $[11,12]$.This recurring contamination of corn by molds such as that of Aspergillus allows the accumulation of aflatoxin in that latter.

Our study revealed high levels of aflatoxin contamination in stored maize of around $40 \%$. This contamination occurs gradually during the different stages of maize management after harvest. This analysis follows the logic of [13], which showed that aflatoxin production increases during post-harvest and storage stages when crops are contaminated. Unlike these latter, the corn crops in our case are not contaminated in the field. In fact, very high levels of aflatoxin have been noted at the level of dried naked ears and stored maize. These two steps represent the crucial points of aflatoxin contamination of corn in this area. The vulnerability of maize to aflatoxin during these two post-harvest stages is directly related to the defective means and methods employed in this area and as in so many others in Africa as summarized so well [2].

\section{Conclusion}

Our study showed that maize before harvest is only slightly attacked by insects and its rate of mold contamination (Aspergillus and Fusarium) is relatively low.

Maize contamination with aflatoxin occurred during postharvest management in Velingara. Two stages of this post-harvest management are particularly crucial in the accumulation of aflatoxin in maize: the drying especially that of the naked ears and the storage of maize. The accumulation of aflatoxin in maize begins during its drying and increases during storage. More than $1 / 4$ of the maize stored in this area is contaminated with aflatoxin. Urgent solutions must be found to prevent aflatoxin contamination of maize. These solutions must take into account the problem of drying and storage.

\section{References}

1. Ahmed NE, Abdalla AE, Adam YS, Betjowck. Fungi and mycotoxins associated with Sorghum grains in major storage systems in Gedarif, Sudan. A paper submitted to the 17th Board of Directors meeting of the national council for mycotoxins, December 2009, Sudanese Standards and Measurements Organisation, Sudan. 2009.
2. Akowuah JO, DzifaMensah L, Chian Chan, Roskilly A. Effects of practices of maize farmers and traders in Ghana on contamination of maize by aflatoxins: Case study of Ejura- Sekyeredumase Municipality. Afric. J.Microbio. 2005;9(25):1658-1666.

3. Alakonya AE, Monda EO, Ajanga S. Fumonisin B1 and Aflatoxin B1 levels in Kenya maize. Journal of Plant Pathology. 2009;91(2):459-464.

4. Broyd H, Dore T. Effets des pratiques agricoles sur la contamination des denrées par les mycotoxines issues de Fusarium et Aspergillus spp. CahAgric. 2013;22(3):182-194.

5. Chebon S, Wanyoike W, Bii C, Gathumbi J, Ogoyi D. Incidence of Aflatoxigenic Fungi and Aflatoxins in Maize Cultivated in Highland and Midaltitude Agro-ecological Zones in Kenya.J. Scientific Res. Reports, 2015;9(6):1-12.

6. FAOSTAT. Food and Agricultural Organisation of the United Nation. 2015.

7. Grintzalis K, Vernardis SI, Klapa MI, Georgiou CD. Role of oxidative stress in sclerotial differentiation and aflatoxin B1 biosynthesis in Aspergillus flavus. Applied and Environmental Microbiology. 2014;80(18):5561-5571.

8. Horn BW. Ecology and population biology of aflatoxigenic fungi in soil. In: Abbas HK, ed. Aflatoxin and food safety. Boca Raton (Florida, USA): Taylor \& Francis Group. 2005;22(2\&3):351-379.

9. James D’Aoust CCA. Moisissures d'épi du maïs. Bulletin agronomique. 2003;2(6).

10. Lewis L, Onsongo M, Njapau H, Schurz- Rogers H, Luber G, Kieszak S. Aflatoxin contamination of commercial maize products during an outbreak of acute aflatoxicosis in eastern and central Kenya. Environ. Health Perspect. 2005;113(12):1763-1767.

11. Medina A, Rodriguez A, Magan N. Effect of climate change on Aspergillus flavus and aflatoxin B1 production. Frontiers in Microbiology. 2014;5:348.

12. Murphy PA, Hendrich S, Landgren C, Bryant CM. Food mycotoxins: An update. J. Food Sci. 2006;71(6):51-65.

13. Muthomi JW, Mureithi BK, Chemining'wa GN, Gathumbi JK, Mutit EW. Aspergillusspecies and Aflatoxin b1 in soil, maize grain and flour samples from semi-arid and humid regions of Kenya. International Journal of Agri Science. 2012;2(1):22-34.

14. Odhiambo BO, Murage H, Wagara IN. Screening for Atoxigenic Aspergillus Species and Evaluating their Inhibitory Potential against Growth and Sporulation of AflatoxigenicAspergillus Species. Afric. J. Micro. Res. 2014;7(34):4379-4388. 